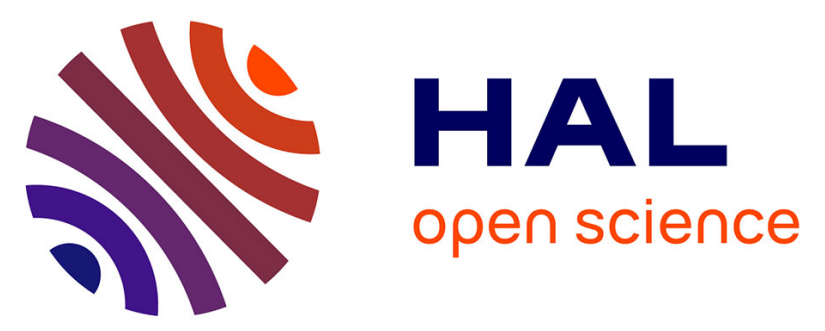

\title{
A semi-automatic analysis tool for the determination of primary particle size, overlap coefficient and specific surface area of nanoparticles aggregates
}

Soleiman Bourrous, Quentin Ribeyre, Laura Lintis, Jérôme Yon, Sébastien Bau, Dominique Thomas, Cécile Vallières, François-Xavier Ouf

\section{To cite this version:}

Soleiman Bourrous, Quentin Ribeyre, Laura Lintis, Jérôme Yon, Sébastien Bau, et al.. A semiautomatic analysis tool for the determination of primary particle size, overlap coefficient and specific surface area of nanoparticles aggregates. Journal of Aerosol Science, 2018, 126, pp.122 - 132. 10.1016/j.jaerosci.2018.09.001 . hal-01877516

\author{
HAL Id: hal-01877516 \\ https://hal.science/hal-01877516
}

Submitted on 19 Sep 2018

HAL is a multi-disciplinary open access archive for the deposit and dissemination of scientific research documents, whether they are published or not. The documents may come from teaching and research institutions in France or abroad, or from public or private research centers.
L'archive ouverte pluridisciplinaire HAL, est destinée au dépôt et à la diffusion de documents scientifiques de niveau recherche, publiés ou non, émanant des établissements d'enseignement et de recherche français ou étrangers, des laboratoires publics ou privés. 


\title{
A semi-automatic analysis tool for the determination of primary particle size, overlap coefficient and specific surface area of nanoparticles aggregates
}

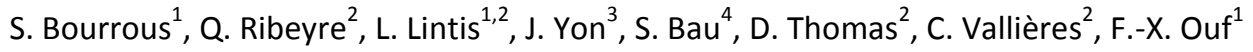 \\ ${ }^{1}$ Institut de Radioprotection et de Sûreté Nucléaire (IRSN), PSN-RES, SCA, Gif-Sur-Yvette, 91192, France. \\ ${ }^{2}$ Université de Lorraine, Laboratoire Réactions et Génie des Procédés (LRGP), UMR 7274, F-54000, Nancy, \\ France. \\ ${ }^{3}$ Normandie Univ, INSA Rouen, UNIROUEN, CNRS, CORIA, 76000 Rouen, France.
}

${ }^{4}$ Institut National de Recherche et de Sécurité, INRS, Laboratoire de Métrologie des Aérosols, Rue du Morvan CS 60027, 54519 Vandoeuvre Cedex, France

\begin{abstract}
$\underline{\text { Abstract }}$
The high reactivity of nanostructured materials makes their use very attractive for various industrial applications. However, these materials may also have an important impact on health / environment / climate and on the performances of protective devices (i.e. high efficiency particulate air filters, electrostatic precipitators). Those properties are mainly due to their high specific surface area, which is directly related to the size of the non-porous primary nanoparticles and to the nature of the bridging between them (from point contact for agglomerates to partial fusion for aggregates).

In this paper, a straightforward image processing has been developed to measure, assuming a log-normal size distribution, the primary particle diameter $\left(D_{p p}\right)$, the geometric standard deviation GSD (or $\sigma_{g}$ ), the projected overlap coefficient $\left(\mathrm{C}_{\mathrm{ov}, \mathrm{p}}\right)$ and the specific surface area (SS) directly from TEM images according to the approach introduced by Bau et al. (2010). Measurements have been performed from TEM images obtained for 22 different kinds of nanoparticles, from simple spheres to soot particles and virtual aggregates. The results show a good agreement (within +/- $20 \%$ ) between automatic and manual analysis of $D_{p p}, \sigma_{g}$ and SS while the overlap coefficient has been compared to the manual analysis showing a reasonable agreement (within +/- $40 \%$ ).
\end{abstract}

Keywords: electronic microscopy, image processing, nanoparticles aggregates / agglomerates, specific surface area.

\section{Introduction}

The study of environmental pollution caused by soot particles is an active research field. Recently, it has been shown that the morphological structure and the overlap coefficient between primary particles composing soot are directly correlated to their optical/radiative properties (Liu et al , 2015; Yon et al., 2014).

Beyond their climate impact, toxicity of those particles is now commonly assumed to have serious public health implications. Several authors have reported that exposure to diesel particulates increases the risk of mortality from lung cancer (Attfield et al., 2012) and that their toxicity is mainly correlated to their specific surface area (Schmid \& Stoeger, 2016; Steiner et al., 2016). The reference method for measuring this specific surface area is based on inert gas adsorption analysis (BET method, Sing, 1985), but as a minimal quantity of powder (at least $100 \mathrm{mg}$ for nanostructured powders from Karg et al., 2008, which represents $10 \mathrm{~m}^{2}$ for $\mathrm{S}_{\text {BET }}=100 \mathrm{~m}^{2} / \mathrm{g}$ ) is needed for such techniques, in certain cases it becomes necessary to derived the specific surface area from TEM images. Usually, determination of the morphological parameters (diameter of the primary particles and overlapping coefficient) from TEM pictures is made manually, which introduces a bias induced by the operator subjectivity and involves a limited number of analyzed images, about 100 depending on the dispersion of the measured parameter. Numerical image processing is a good compromise to improve the quality of those 
measurements and avoid the uncertainty related to subjectivity of the operator. If recent developments have mainly focused on the determination of the size of primary particles and the fractal dimension of the agglomerates/aggregates (Bescond et al., 2014; Dastanpour et al. 2016; Mirzaei \& Rafsanjani, 2017), limited work has been performed regarding the overlap coefficient between primary particles (De Temmerman et al., 2014). To our best knowledge, there is no recent study dealing specifically with the issue of the automated determination of the specific surface area based on TEM image analysis.

Because of the potential health effects of such particles, it is necessary to develop suitable reduction devices such as High Efficiency Particulate Air Filters (HEPA), electrostatic precipitators or scrubbers. All these devices require the efficiency to be as high as possible in order to avoid any release of NOAA (NanoObjects, their Agglomerates and Aggregates) nanostructured particles in the atmosphere or human exposure. Nevertheless, for such situations, the pressure drop induced by the formation of a soot cake at the filtration medium surface represents a significant economic cost. Furthermore, for safety application and especially in the nuclear industry, containment of hazardous particulate materials must be maintained despite the situation. Prediction of airflow behavior of containment elements such as HEPA filters in case of fire directly depends on the properties of the particulate pollutants (Ishibashi et al., 2014; Ouf et al., 2014). In the currently used phenomenological models of filter clogging (Bourrous et al., 2016; Kim et al., 2009; Thomas et al., 2014), the pressure drop of a filter clogged by soot particles can only be estimated from the primary particles size and the overlap fraction of particles between them. Nevertheless, most of the commercially available online measurements (Scanning Mobility Particle Sizer (SMPS), Aerodynamic Particle Sizer (APS), Electrical Low Pressure Impactor (ELPI)) only provide/report an equivalent diameter relative to the physical behavior of aggregates (settling velocity, electrical mobility...). None of them is able to determine in a direct way the primary particle size distribution and their overlap coefficient.

In most cases, Transmission Electron Microscopy is the reference method (Brasil et al., 1999; Köylü et al., 1995) for measuring the morphological properties of fractal aggregates formed during combustion processes. Since the application of Mandelbrot's fractal theory by Jullien \& Botet (1987) for describing the shape of nanoparticles aggregates/agglomerates formed by diffusion limited cluster aggregation (DLCA), many authors have proposed automatic tools for measuring the diameter of primary particles. Such developments were motivated by the need to reduce the time of analysis, to increase the statistics and finally to avoid as much as possible any human operator subjectivity. The latter effect has been investigated in the present work from TEM images of soot particles produced by an ethylene diffusion burner and sampled on TEM grids (Ouf et al., 2010). Manual analysis by two separate human operators was carried out for the same samples and the corresponding mean primary particle diameters are compared in figure $1 \mathrm{a}$. The agreement between each operator appears to be reasonable within a confidence interval of $+/-20 \%$. Other authors (Anderson et al. 2017; Kondo et al. 2013) reported similar fluctuations for flame spray soot (respectively +/- $14 \%$ and +/- $17 \%$ from these sources). Then, +/- $20 \%$ will be considered as the maximum acceptable discrepancy between the proposed automatic analysis and a manual one of primary particle diameter. Similar comparison has been conducted for the overlap coefficient and the results are presented in figure $1 \mathrm{~b}$. For this parameter, the discrepancy between the results obtained by two operators can reach nearly $35 \%$. This bias can be problematic for predictive computations based on this value and for any application that (would) require(s) a fine knowledge of the particles properties/reactivity or toxicity (Schmid \& Stoeger, 2016; Steiner et al., 2016). 

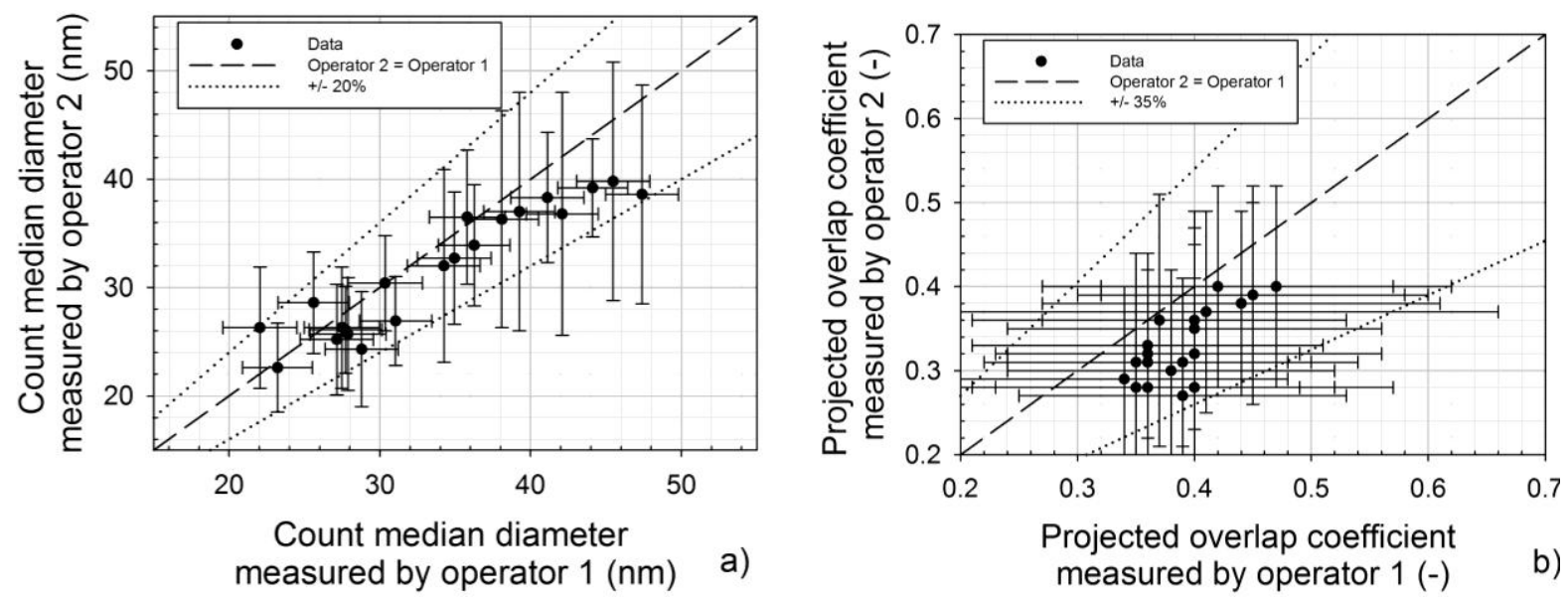

Figure 1: Comparison between count median primary spheres diameters (a) and projected overlap coefficients (b) measured by two human operators for soot particles produced by an ethylene diffusion flame (adapted from Ouf et al., 2010). Bars represent standard deviations.

Manual analysis of the determination of primary particle size and overlap coefficient also remains problematic in terms of statistical validity of the data. Moreover, the duration of the measurement does not allow a high numbers of analyses, typically less than 20. This can influence the statistical representativeness of the measured values. To investigate the influence of the number of measurements required to carry out an accurate statistical analysis of the primary particle, mean diameter has been determined for several sets of data with a wide range of primary particle diameters. This analysis has been carried out for synthetic TEM images of Diffusion Limited Cluster Aggregates and real TEM micrographs of ethylene and gloves box soot particles (see Materials and Methods for more details). Figure 2 shows the evolution, as a function of the number of primary particles diameters considered, of the absolute deviation ( $\operatorname{Dev}\left(\mathrm{N}_{\mathrm{pp} \text { analyzed }}\right)$ ) between mean diameter obtained for a specific number of analyses of primary particles $\mathrm{N}_{\mathrm{pp} \text { analyzed }}$ and the mean diameter obtained from the entire set of images (relation I).

$$
\operatorname{Dev}\left(\mathrm{N}_{\mathrm{pp} \text { analyzed }}\right)=\frac{\left|\overline{\mathrm{Dp}_{\mathrm{Npp}}-\mathrm{Dpp}_{1000}}\right|}{\overline{\mathrm{Dpp}_{1000}}}
$$

With $\mathrm{N}_{\mathrm{pp} \text { analyzed, }}$ the number of primary particles considered, $\overline{\mathrm{Dpp}}$ the mean primary particle size.

The numerical DLCA aggregates with a perfectly known diameter distribution (nearly 400 aggregates

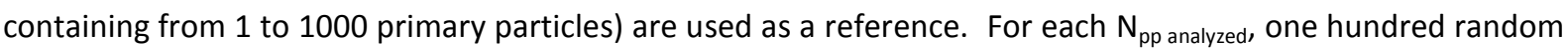
sets of $\mathrm{N}_{\mathrm{pp} \text { analyzed }}$ primary particles are generated and the absolute deviation is computed. Mean value is then determined and reported in figure 2. For the worst case and similarly to the results reported by Bau et al. (2010), a minimum number of 100 primary particles is needed to reach less than $5 \%$ deviation. Nevertheless, the geometric standard deviation has a significant influence on the limiting $\mathrm{N}_{\mathrm{pp} \text { analyzed }}$ and, as GSD decreases from 1.7 to 1.3 (for DLCA), this limiting value decreases by a factor of 5 . In order to check the validity of this numerical approach, those are compared with two different kinds of aggregates with various sample sizes denoting a limited number of aggregates (14 glove box soot aggregates) and a reasonable one (81 fresh ethylene soot aggregates). As demonstrated by Dastanpour \& Rogak (2014), the amount of aggregates plays a rule in the statistical representativity of the primary particle size distribution. In our case, for the glove box sample, 14 aggregates (associated to 50 primary particles) are enough to reach a statically satisfying distribution, even for a GSD of 1.5. Without any prior knowledge on the GSD of primary particle size distribution, a minimum number of 100 measurements of primary particle diameter is needed (assuming that GSD does not exceed 1.7). 


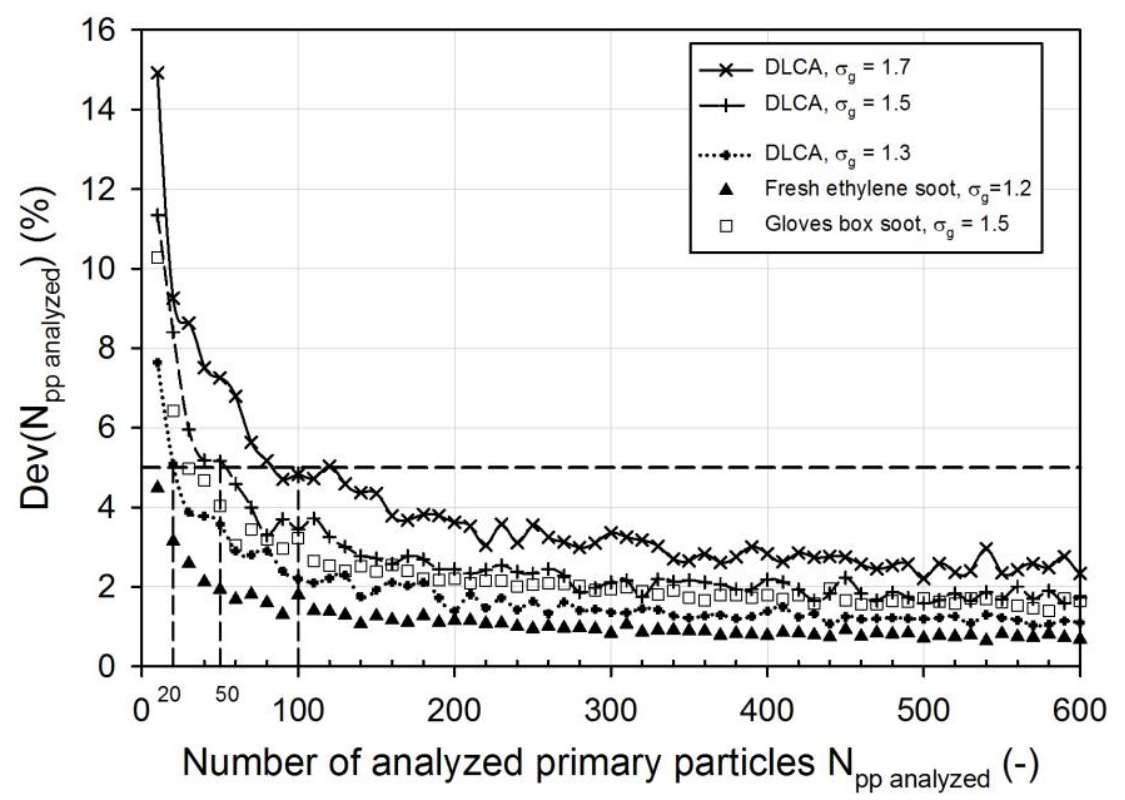

Figure 2: Evolution of mean primary particle diameter of ethylene soot particles (adapted from Ouf et al., 2010) as a function of number of primary particle diameters considered

Beyond the definition of aggregate and agglomerates of nanoparticles, it can be helpful to introduce a relevant metric for describing the bridging between nanoparticles and moreover for describing their physical and chemical behavior. For this purpose, Brasil et al. (1999) have introduced the overlap coefficient $C_{o v}$ as a function of the mean primary particle diameter and the distance between the centers of mass of two contiguous nanoparticles. Beyond the description of the bridging between soot or nanoparticles aggregates/agglomerates, several recent studies have demonstrated that this property could have an indirect influence on soot optical properties through modification of their morphological properties (Yon et al., 2015), pressure drop associated with soot or nanoparticles cake (Thomas et al., 2014) as well as their specific surface area (De Temmerman et al., 2014).

According to Brasil et al.'s relationship between three-dimensional and projected properties and using primary particle diameter, overlap coefficient and assuming the soot bulk density, Gwaze et al. (2006) were the first authors to apply the specific surface determination from TEM pictures for soot particles. More recently, Bau et al. (2010) have validated this approach (see relation III) by comparing TEM-based analysis with specific surface area measurements according to the reference BET method (Brunauer et al., 1938; Sing, 1985). Nevertheless, such analysis, generally operated manually, suffers a lack of statistics, is extremely time consuming and denotes high level of uncertainty.

To overcome those difficulties, some authors have developed image processing algorithms in order to analyze a statistically relevant number of primary particles (more than 100 to reach less than $5 \%$ deviation according to fig. 2). Several methods have been recently proposed to measure the primary particle diameter (Kook et al., 2015; Mirzaei \& Rafsanjani, 2017), the geometric standard deviation of their size distribution (Bescond et al., 2014; Dastanpour et al., 2016), the aggregates/agglomerates fractal dimension (Wang et al., 2016) and even the overlap coefficient of primary particles (De Temmerman et al., 2014). It is worth noting that none of those methods allows the measurement of the specific surface area.

In the present work, a new semi-automatic measurement process of $\mathrm{D}_{\mathrm{PP}}, \sigma_{\mathrm{g}}, \mathrm{C}_{\mathrm{OV}}$ and $\mathrm{SS}$ is proposed, based on the Hough transform (Matlab C , Grishin et al., 2012). Automatic analysis of $D_{p p}, \sigma_{g}, C_{o v}$ has been validated using a wide range of real and model nanoparticles (Bescond et al., 2013) on the basis of manual measurement of these morphological parameters. Application of this automatic method to the determination of the specific surface area has been finally validated according to BET measurements. 


\section{Materials and methods}

The presented program aims to analyze raw TEM images without prior processing. To do so, raw images are pretreated using classical binarization and opening process. This aims to reduce the noise and to ensure the proper selection of the particles. Various automatic binarization methods exist to ensure the selection of the optimal threshold. Our program uses the simple and fast method proposed by Otsu (Otsu, 1979). It is based on the assumption that only the background and the particle are present on the picture. When images contrast is too low to ensure the analyzability, a manual thresholding can also be used. The criterion for this step is to be able to distinguish the primary particles constituting the aggregate.

In a second step, circular structures are found using the Hough transform preprogrammed function and their diameter and position are used to identify overlapping particles. To do so, the input parameters are the sensitivity, the maximal and minimal radius of each mode visually identified (in order to reduce the processing time and to make the measurement more accurate). Furthermore, a visual control is performed by the operator consecutively to the analysis of each processed image, in order to avoid any artefact. Figure 3 shows an illustration of the analysis performed on a fractal soot aggregate.
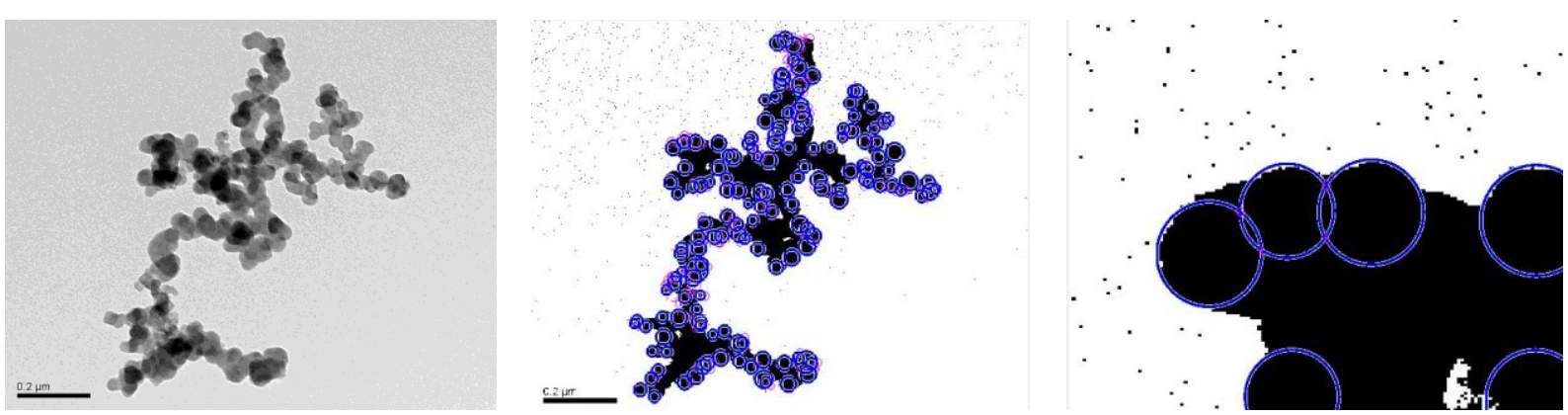

Figure 3: Illustration of the primary particle diameter and overlap coefficient measurement process

Recognized particles are identified by blue circles on the right image (after treatment). It is worth noting that all of the particles are not systematically detected. Due to the low quality of the input image and the intrinsic principle of the Hough transform, an exhaustive automatic detection of the particles cannot be performed. The representativeness of the statistical analysis is based on the fact that a high number of images can be analyzed successively since analyses are performed within a few seconds. Projected overlap coefficient $\left(C_{o v, p}\right)$ is measured on the TEM images according to the respective positions of the centers of mass and diameters of each overlapping primary particles and the empirical correlation of (Brasil et al., 1999) is used to convert the 2D $\mathrm{C}_{\mathrm{ov}, \mathrm{p}}$ into a $3 \mathrm{D} \mathrm{C}_{\mathrm{ov}}$.

$$
C_{o v}=1.1 C_{o v}, p^{-0.2}
$$

In the present software, for each couple of circles detected, the distance between the centers is compared to the sum of the radius. If this distance is lower, then one $\mathrm{C}_{\mathrm{OV}, \mathrm{p}}$ value is considered. This process is repeated for all particles detected in the image. One must noticed that present relationship is purely empirical and, as reported by Brasil et al. (1999), has been developed for soot aggregates with a fractal dimension of 1.78 and a projected overlap coefficient $\mathrm{C}_{\mathrm{ov}, \mathrm{p}}$ ranging from 0 to 0.33 .

From this value, using the relation firstly introduced by Brasil et al. (1999) and modified by Bau et al. (2010), the specific surface area, defined as the ratio between particle geometric surface area and mass, has been deduced by knowing or assuming the bulk density of the material composing nanoparticles $\rho_{\mathrm{pp}}$. 


$$
\mathrm{SS}=\frac{6}{\rho_{\mathrm{pp}}}\left[1-\Phi \mathrm{C}_{\mathrm{ov}}\left(1-\frac{1}{\mathrm{~N}_{\mathrm{pp}}}\right)\right] \frac{\sum_{\mathrm{dpp}_{\mathrm{p}}} \mathrm{N}\left(\mathrm{d}_{\mathrm{pp}}\right) \mathrm{d}_{\mathrm{pp}}^{2}}{\sum_{\mathrm{dpp}_{\mathrm{p}}} \mathrm{N}\left(\mathrm{d}_{\mathrm{pp}}\right) \mathrm{d}_{\mathrm{pp}}^{3}}
$$

With $\Phi$ an empirical constant equal to 1.3 according to Brasil et al. (1999). As mentioned by Bau et al. (2010), this method of specific surface area analysis has been validated on non-porous nanoparticles aggregates with different primary particle diameters ranging from $7 \mathrm{~nm}$ to $47 \mathrm{~nm}$ and projected overlap coefficient between 0 (agglomerates) and 0.24 ( $\mathrm{SiO}_{2}$ aggregates). The corresponding specific surface area covered a range from 36.9 to $198.3 \mathrm{~m}^{2} / \mathrm{g}$ and the main assumption in this previous study was to consider that the specific surface area measured on an aerosol sample (after dispersion in the airborne phase of a nanostructured powder) is similar to the one of the bulk powder as measured by the BET method.

In this work, the validation protocol has been performed in 3 steps by 3 independent human operators:

1. First of all, ideal 3D aggregates have been simulated using a DLCA code; this method allows the control of the particle size distribution, fractal dimension and overlap coefficient. This validation step performed on ideal objects aims to validate the choice of the method, statistical representativeness and correlations (Brasil et al., 1999; Bau et al., 2010) which are used in the program.

2. Secondly, evaluation of the robustness of the measurement has been performed on nonaggregated nanoparticles. In this step, the TEM images considered have been produced in the frame of a metrological work (Motzkus et al., 2013) and the geometric properties have been manually measured by different laboratories. Those images will be used as a reference for the validation of the number size distribution of primary particle diameter to evaluate the impact of image noise, background and contrast.

3. Finally TEM images of aggregates found in the literature or produced for this work have been manually analyzed for validating the automatic analysis of $D_{p p}, \sigma_{g}$ and $C_{o v}$ while the specific surface area of the particles was compared to reference BET values obtained on powder samples. The robustness of the program with realistic fire particulate emissions was evaluated on soot aggregates produced by laboratory scale burners as well as soot particles emitted in real fire conditions. All validations have been performed on more than 100 primary particles according to the results presented in figure 2 and allowing a good statistical representativeness (less than $5 \%$ relative deviation on primary particle diameter).

Morphological properties and examples of images (TEM based or numerical) of the different samples considered are summarized in Tables 1 and 2. Reference values of bulk density and BET specific surface area are also reported in these tables with the corresponding reference when coming from literature. Sampling of these particles has been carried according to thermophoretic particle sampler (TPS, Ouf et al., 2010), filtration on nuclepore membrane of colloidal suspension dispersed according to a pneumatic generator (mentioned as filtration in table 1, Motzkus et al., 2013), deposition of a droplet of colloidal suspension directly on TEM grids (mentioned as droplet in table 1, Ribeyre, Grévillot, Charvet, Vallières, \& Thomas, 2014) mini particle sampler (MPS, R'mili, Le Bihan, Dutouquet, Aguerre-Charriol, \& Frejafon, 2013) and corresponding methods are summarized in table 1. TEM analyses have been carried out using several transmission electron microscope, i.e. 120 kV Zeiss, EM 910 model (Aerosil 200 and Black carbon samples) and 100kV JEOL, 100CXII model (others samples).

\section{Validation of the automatic measurement tool}

\section{Automatic analysis of primary particle size distribution}

The comparison between the count median diameter measured manually and by the automated software for all samples described in Tables 1 and 2 is presented in figure 4 . For the 3 different synthetic aggregates 
obtained with the DLCA code, the agreement is almost perfect, with a mean discrepancy of $2 \%$ or $0.4 \mathrm{~nm}$ (corresponding to 2 pixels according to the resolution of the numerical images of $0.2 \mathrm{~nm}$ per pixel). As for TEM images obtained for real samples, no significant difference has been noticed between manual and automatic analysis. Among the 21 samples tested, the deviation exceeds $20 \%$ for only 3 samples (commercial Aerosil 200 and soot particles sampled during Gloves box and Hydraulic oil fires). This might be due to an excessive noise or possible limited resolution of those TEM images. Nevertheless, this order of magnitude of deviation is similar to the bias expected for manual analysis between two separated human operators, as shown in figure 1 . The automated approach developed in the present study is then considered suitable for analyzing real nanoparticles and soot samples with high level of confidence. According to Motzkus et al. (2013) and Bescond et al. (2014), a log-normal function has been considered for describing the primary particle size distribution of respectively nanoparticles (excepted for PSL which is a mono-disperse size standard) and soot samples. Figure 4 also presents the comparison between the geometric standard deviation determined from the automatic size distribution analysis and the one measured manually. For the reference images (i.e. generated using the DLCA code), the geometric standard deviation obtained manually is almost perfectly corresponding to the expected value. Small discrepancies are doubtless due to the resolution of the image. For the real TEM images, except for the Aerosil 200, the correspondence is within $20 \%$ which is lower than the uncertainty and bias inherent to the human subjectivity during the manual analysis (20\% from figure 1). This validates the concept of the measurement and its statistical representativeness. 
Table 1: Properties of reference samples considered for validation of the automated measurement process

\begin{tabular}{|c|c|c|c|c|c|c|c|c|c|}
\hline \multirow[b]{2}{*}{ Type } & \multirow[b]{2}{*}{ Name } & \multirow[b]{2}{*}{ Source } & \multicolumn{3}{|c|}{ Manual TEM analysis } & \multirow[b]{2}{*}{$\mathrm{S}_{\mathrm{BET}}\left(\mathrm{m}^{2} / \mathrm{g}\right)$} & \multirow{2}{*}{ Density $\left(\mathrm{kg} / \mathrm{m}^{3}\right)$} & \multirow{2}{*}{$\begin{array}{c}\text { Reference } \\
\text { (sampling method) }\end{array}$} & \multirow{2}{*}{$\begin{array}{l}\text { Examples of TEM or numerical } \\
\text { images }\end{array}$} \\
\hline & & & $\overline{\overline{D_{p p}}}(\mathrm{~nm})$ & $\sigma_{g}(-)$ & $C_{\mathrm{ov}, \mathrm{p}}(-)$ & & & & \\
\hline \multirow[t]{3}{*}{ DLCA } & DLCA1 & \multirow{3}{*}{$\begin{array}{l}\text { Diffusion limited } \\
\text { cluster aggregation } \\
\text { code }\end{array}$} & 20.3 & 1.31 & - & - & - & \multirow{3}{*}{$\begin{array}{l}\text { DLCA code from Bescond } \\
\text { et al. (2013) }\end{array}$} & \\
\hline & DLCA2 & & 20.4 & 1.51 & - & - & - & & \\
\hline & DLCA3 & & 19.8 & 1.72 & - & - & - & & \\
\hline \multirow[t]{6}{*}{ Nanoparticles } & PSL, 102 nm & \multirow{2}{*}{$\begin{array}{l}\text { Polystyrene latex } \\
\text { sphere }\end{array}$} & 102 & - & - & - & - & \multirow{2}{*}{$\begin{array}{c}\text { Duke scientific } \\
\text { (filtration) }\end{array}$} & \\
\hline & PSL, 199 nm & & 199 & - & - & - & - & & \\
\hline & $\mathrm{SiO}_{2}$ & LUDOX & 33.0 & 1.14 & - & $140^{1}$ & $1400^{1}$ & $\begin{array}{c}{ }^{1} \text { Manufacturer datasheet } \\
\text { (filtration) }\end{array}$ & \\
\hline & Si & IRAMIS & 23.7 & 1.33 & - & 87 & 2327 & $\begin{array}{c}\text { Manufacturer datasheet } \\
\text { (filtration) }\end{array}$ & \\
\hline & Aerosil 200 & DEGUSSA & 21.3 & 1.28 & & $196+/-1$ & $2580^{2}$ & $\begin{array}{c}{ }^{2} \text { Manufacturer datasheet } \\
\text { (droplet) }\end{array}$ & \\
\hline & Black Carbon & PROLABO & 142 & 1.30 & - & $30.3+/-1$ & $1869^{3}$ & $\begin{array}{c}{ }^{3} \text { Manufacturer datasheet } \\
\text { (droplet) }\end{array}$ & \\
\hline
\end{tabular}

$\overline{\mathbf{D}_{\mathbf{p p}}}$ : count median diameter of primary particle $(\mathrm{nm}), \sigma_{\mathrm{g}}$ geometric standard deviation $(-), \mathrm{C}_{\mathrm{oup}}$ : projected overlap coefficient $(-), \boldsymbol{S}_{\mathrm{B} e \mathrm{r}}$ : specific surface area measured by BET $\left(\mathrm{m}^{2} / \mathrm{g}\right)$ 
Table 2: Properties of soot samples considered for validation of the automated measurement process

\begin{tabular}{|c|c|c|c|c|c|c|c|c|c|c|}
\hline \multirow{2}{*}{\begin{tabular}{|l} 
Type \\
\end{tabular}} & \multirow{2}{*}{ Name } & \multirow{2}{*}{ Source } & \multicolumn{3}{|c|}{ Manual TEM analysis } & \multirow{2}{*}{$\mathrm{S}_{\mathrm{BET}}\left(\mathrm{m}^{2} / \mathrm{g}\right)$} & \multirow{2}{*}{ Density $\left(\mathrm{kg} / \mathrm{m}^{3}\right)$} & \multirow{2}{*}{$\begin{array}{c}\text { Reference } \\
\text { (sampling method) }\end{array}$} & \multirow{2}{*}{\multicolumn{2}{|c|}{$\begin{array}{l}\text { Examples of TEM or numerical } \\
\text { images }\end{array}$}} \\
\hline & & & $\overline{\mathrm{D}_{\mathrm{pp}}}(\mathrm{nm})$ & $\sigma_{g}(-)$ & $C_{o v, p}(-)$ & & & & & \\
\hline \multirow[t]{14}{*}{ Soot particles } & Fresh ethylene soot & \multirow{3}{*}{$\begin{array}{l}\text { Ethylene diffusion } \\
\text { burner }\end{array}$} & 28.8 & 1.18 & $0.13+/-0.12$ & - & - & \multirow{3}{*}{$\begin{array}{l}\text { Ouf et al. (2010) } \\
\text { (TPS) }\end{array}$} & & \\
\hline & Aged ethylene soot & & 27.1 & 1.17 & $0.21+/-0.12$ & - & - & & & \\
\hline & & & & & & & & & Fresh & Aged soot \\
\hline & CAST 50/100/1.2 & \multirow[t]{2}{*}{$\begin{array}{l}\text { Propane diffusion } \\
\text { burner miniCAST }\end{array}$} & 23.3 & 1.15 & $0.29+/-0.12$ & - & 1745 & $\begin{array}{l}\text { Thomas et al. (2014) } \\
\text { (TPS) }\end{array}$ & \multirow{2}{*}{\multicolumn{2}{|c|}{ CAST $50 / 100 / 1.2$ CAST $60 / 0 / 1.5$}} \\
\hline & CAST 60/0/1.5 & & 26.5 & 1.36 & $0.28+/-0.09$ & $137.2+/-0.5^{4}$ & $1543^{5}$ & $\begin{array}{c}{ }^{4} \text { Monge et al. (2010) } \\
{ }^{5} \text { Yon et al. (2015) } \\
\text { (TPS) }\end{array}$ & & \\
\hline & $\begin{array}{l}\text { Heptane flame, } \\
21 \%\left[\mathrm{O}_{2}\right]\end{array}$ & \multirow[t]{2}{*}{$\begin{array}{l}\text { Medium scale } \\
\text { heptane pool fire }\end{array}$} & 35.1 & 1.31 & $0.30+/-0.13$ & - & - & $\begin{array}{l}\text { Present paper } \\
\text { (TPS) }\end{array}$ & & \\
\hline & $\begin{array}{l}\text { Heptane flame, } \\
15 \%\left[\mathrm{O}_{2}\right]\end{array}$ & & 31.2 & 1.32 & $0.29+/-0.14$ & - & - & $\begin{array}{l}\text { Present paper } \\
\text { (TPS) }\end{array}$ & Heptan & \\
\hline & Heptane pool fire & $\begin{array}{l}\text { Medium scale pool } \\
\text { fire, confined }\end{array}$ & 42.0 & 1.35 & $0.28+/-0.13$ & - & - & $\begin{array}{l}\text { Present paper } \\
\text { (MPS) }\end{array}$ & & \\
\hline & Hydraulic oil flame & $\begin{array}{l}\text { Small scale, over- } \\
\text { ventilated }\end{array}$ & 47.7 & 1.81 & $0.34+/-0.11$ & - & - & $\begin{array}{c}{ }^{6} \text { Ouf et al. (2014) } \\
\text { (MPS) }\end{array}$ & & \\
\hline & $\begin{array}{l}\text { Polycarbonate } \\
\text { flame }\end{array}$ & & 52.77 & 1.60 & $0.29+/-0.11$ & - & - & & & \\
\hline & PMMA/PVC flame & $\begin{array}{l}\text { Medium scale, } \\
\text { under-ventilated }\end{array}$ & 72.0 & 1.19 & $0.30+/-0.11$ & $57.2+/-5.0$ & 1260 & $\begin{array}{c}\text { Present paper } \\
\text { (filtration) }\end{array}$ & & \\
\hline & Gloves box fire & $\begin{array}{l}\text { Large scale, over- } \\
\text { ventilated }\end{array}$ & 41.8 & 1.47 & $0.36+/-0.11$ & $43.8+/-0.1$ & 1660 & $\begin{array}{c}\text { Present paper } \\
\text { (MPS) }\end{array}$ & & \\
\hline & Hydraulic oil fire & $\begin{array}{l}\text { Large scale, over- } \\
\text { ventilated }\end{array}$ & 47.3 & 1.46 & $0.34+/-0.15$ & $77.1+/-1.3$ & 1614 & $\begin{array}{l}\text { Present paper } \\
\text { (MPS) }\end{array}$ & & \\
\hline & Aircraft soot & $\begin{array}{l}\text { SAM146 engine, } \\
85 \% \text { thrust }\end{array}$ & 16.7 & 1.54 & - & - & - & $\begin{array}{c}{ }^{7} \text { Bescond et al. (2014) } \\
\text { (MPS) }\end{array}$ & & \\
\hline
\end{tabular}

$\overline{\mathbf{D}_{\mathrm{pp}}}$ : count median diameter of primary particle $(\mathrm{nm}), \mathbf{\sigma}_{\mathrm{g}}:$ geometric standard deviation $(-), \mathbf{C}_{\mathrm{ov}, \mathrm{p}}$ : projected overlap coefficient $(-), \mathbf{S}_{\mathrm{BET}}$ : specific surface area measured by BET $\left(\mathrm{m}^{2} / \mathrm{g}\right)$ 


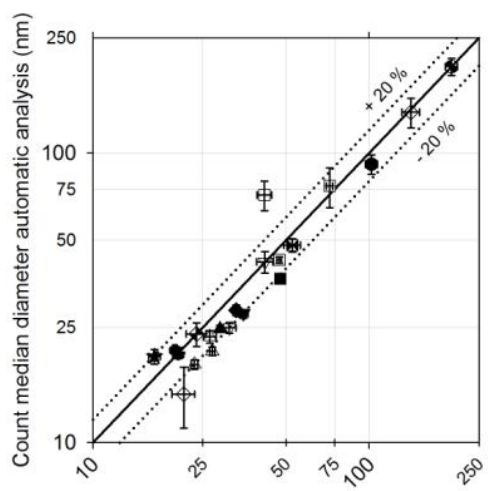

a) Count median diameter manual analysis $(\mathrm{nm})$
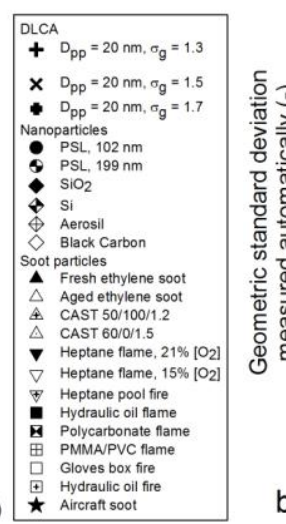

DLCA $+D_{P P}=20 \mathrm{~nm}, \sigma_{g}=1.3$ X $D p p=20 \mathrm{~nm}, \mathrm{~g}=1$. - Dpp $=20 \mathrm{~nm}, \sigma_{g}=1.7$ Nenopertices - $\mathrm{SiO}_{2}$

Soot particles
Fresh ethylene so Aged ethylene soo CAST 60/0/1.5

Heptane flame, 21\% [02]

Heptane flame, $15 \%\left[\mathrm{O}_{2}\right]$

Heptane pool fire Heptane pool fire
Hydraulic oil flame Hydraulic oil fiame
Polycarbonate flame PMMAIPVC flame Gloves box fire Hydraulic oil fire Aircratt soot

b)

Figure 4: comparison between count median diameter and geometric standard deviation associated to primary particles, measured by the automated software or manually (standard errors at $95 \%$ confidence interval)

\section{Automatic analysis of the overlap coefficient}

Measuring the overlap coefficient remains difficult especially to reach a statistically significant value. The measuring process is based on the detection of circles that touch each other as shown in figure 3. However, when the overlapping of two particles is too high, it is difficult to identify their circular shape. Furthermore, the manual measurement can also be affected by the human subjectivity (see figure $1 \mathrm{~b}$ ) and such artifacts mainly explained the high level of deviation reported by previous authors (from $15 \%$ to $40 \%$ for soot particles studied by Ouf et al., 2010 and Thomas et al., 2014).

Comparison between manually and automatically measured projected overlap coefficients is presented in figure 5. For all samples, and considering the corresponding standard deviation of each $\mathrm{C}_{\mathrm{ov}, \mathrm{p}}$, the values obtained automatically or manually are in agreement within $40 \%$ (see figure $5 a$ ) with a slight trend of underestimation of the automatic method versus the manual one. One could also notice that the overall trend is globally respected for both methods (see figure $5 \mathrm{~b}$ ). Furthermore, for soot particles, $\mathrm{C}_{\mathrm{ov}, \mathrm{p}}$ is ranging from 0.21 to 0.38 , close to values reported in literature (Gwaze et al., 2006; Ouf et al., 2010; Thomas et al., 2014).
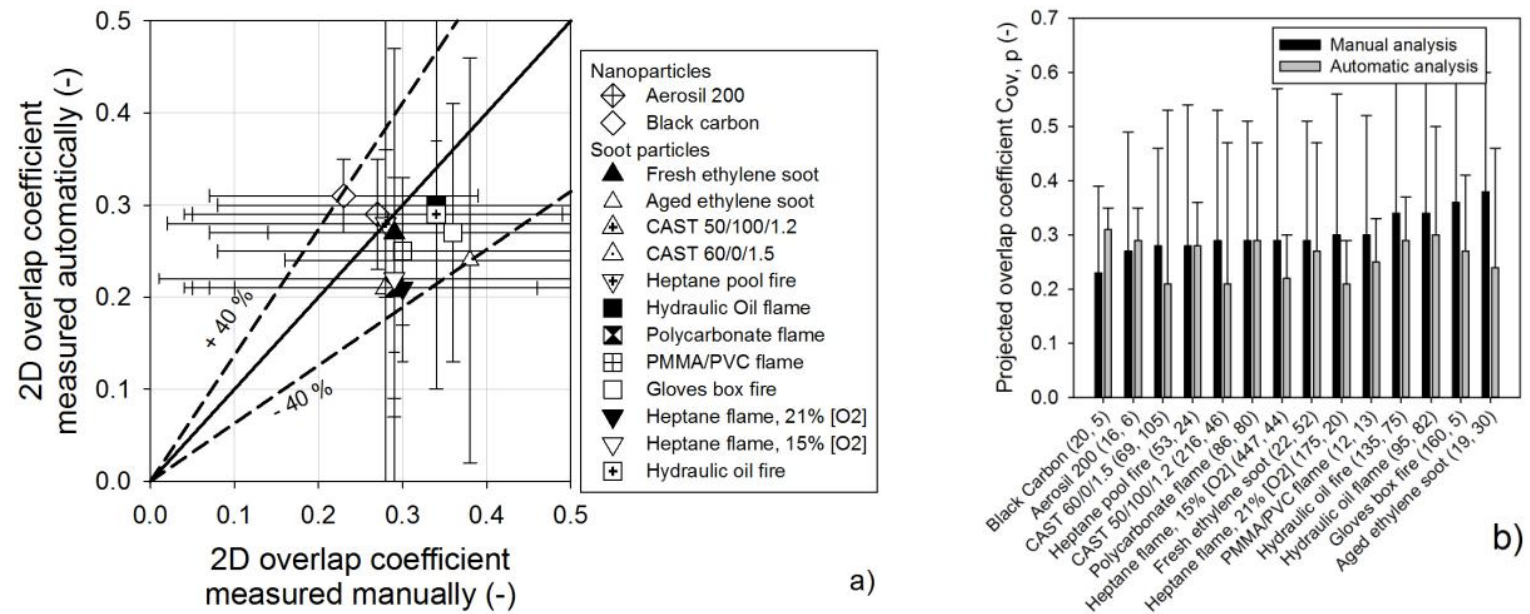

Figure 5: comparison between overlap coefficients measured manually or automatically (the number of measurements (manual, automatic) are presented under brackets on figure $b$ after the samples references)

Since this analysis is extremely time consuming and sensitive to an "operator effect", results presented in figure 5 confirm that the proposed automatic approach is, at least, as relevant as a manual analysis and does not denote higher level of deviation than the one associated with "human perception" (35\% from figure $1 \mathrm{~b}$ ). From these results, it can be considered that the automatic analysis method is able to measure the primary 
particle diameter, the geometric standard deviation and the overlap coefficient with satisfying accuracy (respectively $20 \%$ for $D_{p p}$ and $\sigma_{g}$ and $40 \%$ for $C_{o v}, p$ ).

\section{Automatic analysis of the specific surface area}

Implementing Bau et al.'s (2010) relationship in our analysis software allows the specific surface area to be determined automatically. Comparison between TEM-based method and BET values (reported in the literature or supplied by the powder manufacturer) is presented in figure 6 . Sensitivity analysis has been also performed for each influencing parameters $\left(\rho_{p p}, C_{o v}, D_{p p}, N_{p p}\right)$ and is reported in Supplementary Material. This analysis shows minor influence of Cov and $\rho_{\mathrm{pp}}$ compared to $\mathrm{D}_{\mathrm{pp}}$ for all considered $\mathrm{N}_{\mathrm{pp}}$ (from 10 to 10 000).

A good agreement (+/- $20 \%$ ) between the proposed method and BET analysis is reported for BET specific surface areas ranging from 30 to $200 \mathrm{~m}^{2} / \mathrm{g}$. BET analysis presents the lowest standard deviation, typically less than $10 \%$ (see Tables 1 and 2), and remains the reference method. Nevertheless, in most cases, and especially for soot particles and more generally aerosols, it is generally tricky to retrieve enough mass of sample (for nanoparticles with $\mathrm{S}_{\mathrm{BET}}=100 \mathrm{~m}^{2} / \mathrm{g}$, a total surface of $10 \mathrm{~m}^{2}$ represents $100 \mathrm{mg}$ which is minimum amount recommended by Karg et al., 2008) to perform a BET analysis. Therefore, developing TEM-based analysis tools to determine the specific surface area of aerosols is of great interest. Such results also confirm the recent findings of Dazon et al. (2017) for nanostructured samples with BET specific surface area within the range 30$500 \mathrm{~m}^{2} / \mathrm{g}$. They reported a good agreement between the specific surface area of the powder (SS Powder$_{\text {r }}$ and the one of the aerosol $\left(\mathrm{SS}_{\text {Aerosol }}\right)$ after aerosolization, both specific surface areas being obtained by the BET method.

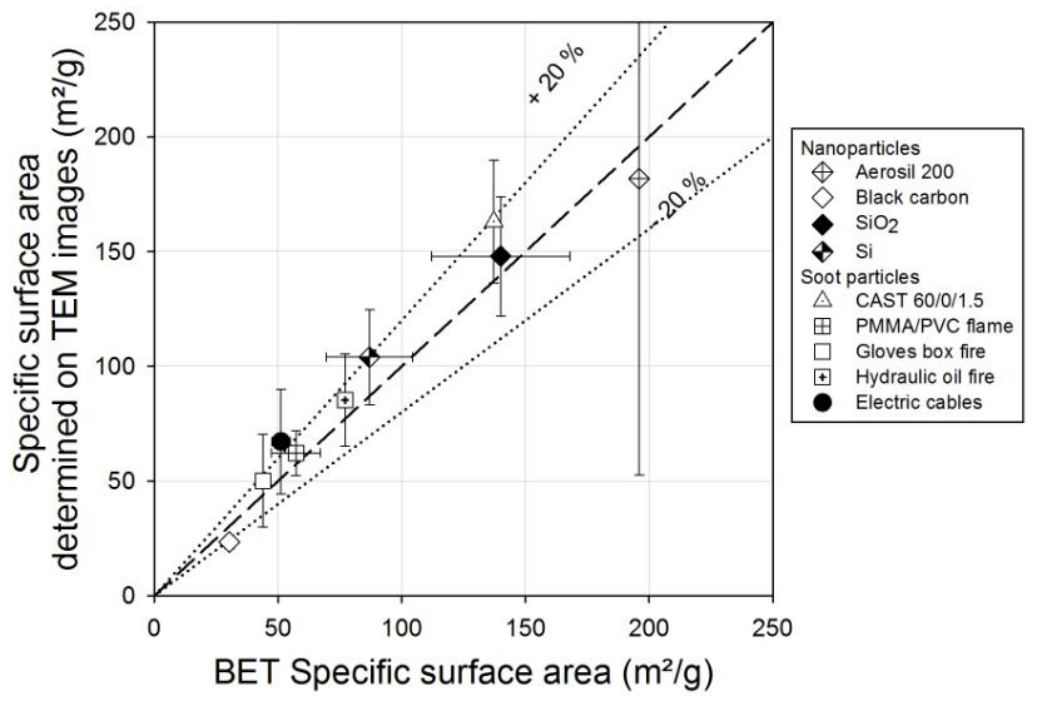

Figure 6: comparison between automatic specific surface area analysis and BET analysis

\section{Conclusions}

Nowadays, most of the aerosol measurement device constructors propose easy to use and cost effective sampling systems that allow airborne particle to be directly collected on TEM grids. Electron microscopy remains the most robust and reference method to characterize nanoparticles at several scales (morphology, size, microstructure ....). Nevertheless, the analysis of TEM images is time consuming and the use of human interface for images analysis involves a lot of questions regarding human subjectivity and measurement reproducibility. The proposed method, based on preprogrammed functions (Hough transform), allows the quantification of the relevant morphological parameters. Then, primary particles diameter, geometric standard deviation and overlap coefficient measured using this automatic tool have been successfully compared to reference manual analysis within a confidence interval similar to the bias induced by human subjectivity (+/- 20 $\%$ for the two firsts and $40 \%$ for $\mathrm{C}_{\mathrm{ov}, \mathrm{p}}$ ). These data have been used to determine the specific surface area, for 
which no convincing comparison has been found in the literature between an automatic analysis tool and reference BET measurements. The present method is, as far as we are concerned, the first automatic method providing reliable values of specific surface area in close agreement to the BET reference method (within an interval of $+/-20 \%$ ). It is worth noting that the present method is limited to non-porous primary particles with known bulk density, which is an acceptable hypothesis for soot particles and most of manufactured nanoparticles.

\section{Acknowledgement}

This work is a part of the LIMA joint research program (The Interactions Media-Aerosol Laboratory) between the Institut de Radioprotection et de Sûreté Nucléaire (IRSN) and the Reactions and Chemical Engineering Laboratory (LRGP) of the French National Centre for Scientific Research (CNRS).

\section{$\underline{\text { References }}$}

Anderson, P. M., Guo, H., \& Sunderland, P. B. (2017). Repeatability and reproducibility of TEM soot primary particle size measurements and comparison of automated methods. Journal of Aerosol Science, 114(October), 317-326. http://doi.org/10.1016/j.jaerosci.2017.10.002

Attfield, M. D., Schleiff, P. L., Lubin, J. H., Blair, A., Stewart, P. A., Vermeulen, R., ... Silverman, D. T. (2012). The diesel exhaust in miners study: A cohort mortality study with emphasis on lung cancer. Journal of the National Cancer Institute, 104(11), 869-883. http://doi.org/10.1093/jnci/djs035

Bau, S., Witschger, O., Gensdarmes, F., Rastoix, O., \& Thomas, D. (2010). A TEM-based method as an alternative to the BET method for measuring off-line the specific surface area of nanoaerosols. Powder Technology, 200(3), 190-201. http://doi.org/10.1016/j.powtec.2010.02.023

Bescond, A., Yon, J., Girasole, T., Jouen, C., Rozé, C., \& Coppalle, A. (2013). Numerical investigation of the possibility to determine the primary particle size of fractal aggregates by measuring light depolarization. Journal of Quantitative Spectroscopy and Radiative Transfer, 126, 130-139. http://doi.org/10.1016/j.jqsrt.2012.10.011

Bescond, A., Yon, J., Ouf, F. X., Ferry, D., Delhaye, D., Gaffié, D., ... Rozé, C. (2014). Automated Determination of Aggregate Primary Particle Size Distribution by TEM Image Analysis: Application to Soot. Aerosol Science and Technology, 48(8), 831-841. http://doi.org/10.1080/02786826.2014.932896

Bourrous, S., Bouilloux, L., Ouf, F.-X., Lemaitre, P., Nerisson, P., Thomas, D., \& Appert-Collin, J. C. (2016). Measurement and modeling of pressure drop of HEPA filters clogged with ultrafine particles. Powder Technology, 289, 109-117. http://doi.org/10.1016/j.powtec.2015.11.020

Brasil, A. M., Farias, T. L., \& Carvalho, M. G. (1999). A recipe for image characterization of fractal-like aggregates. Journal of Aerosol Science, 30(10), 1379-1389. http://doi.org/10.1016/S00218502(99)00026-9

Brunauer, S., Emmett, P. H., \& Teller, E. (1938). Adsorption of Gases in Multimolecular Layers. Journal of the American Chemical Society, 60(2), 309-319. http://doi.org/10.1021/ja01269a023

Dastanpour, R., Boone, J. M., \& Rogak, S. N. (2016). Automated primary particle sizing of nanoparticle aggregates by TEM image analysis. Powder Technology, 295, 218-224. http://doi.org/10.1016/j.powtec.2016.03.027

Dastanpour, R., \& Rogak, S. N. (2014). Observations of a Correlation Between Primary Particle and Aggregate Size for Soot Particles. Aerosol Science and Technology, 48(10), 1043-1049. http://doi.org/10.1080/02786826.2014.955565

Dazon, C., Witschger, O., Bau, S., Payet, R., Fierro, V., \& Jensen, K. A. (2017). On the equivalence between massspecific surface area of powders and their aerosols and proposal of a new dustiness index for bulk nanomaterials Prediction and quantification of emissions and workers exposure during ceramic industrial 
processes. In European Aerosol Conference (p. 2017). Zurich,.

De Temmerman, P. J., Verleysen, E., Lammertyn, J., \& Mast, J. (2014). Semi-automatic size measurement of primary particles in aggregated nanomaterials by transmission electron microscopy. Powder Technology, 261, 191-200. http://doi.org/10.1016/j.powtec.2014.04.040

Grishin, I., Thomson, K., Migliorini, F., \& Sloan, J. J. (2012). Application of the Hough transform for the automatic determination of soot aggregate morphology. Applied Optics, 51(5), 610-20. http://doi.org/10.1364/AO.51.000610

Gwaze, P., Schmid, O., Annegarn, H. J., Andreae, M. O., Huth, J., \& Helas, G. (2006). Comparison of three methods of fractal analysis applied to soot aggregates from wood combustion. Journal of Aerosol Science, 37(7), 820-838. http://doi.org/10.1016/j.jaerosci.2005.06.007

Ishibashi, T., Tsuchino, S., Matsumoto, S., \& Kasahara, F. (2014). Clogging of HEPA filters by soot during fire events in nuclear fuel cycle facilities. Nuclear Te, 187, 57-68.

Jullien, R., \& Botet, R. (1987). Aggregation and Fractal aggregates. World Scientific Publishing Co Pte Ltd.

Karg, E., Ferron, G. A., Schumann, G., \& Schmid, O. (2008). Specific BET Surface Area Measurement of LowMass-Samples. In 12th ETH Conference on Combustion Generated Nanoparticles.

Kim, S. C., Wang, J., Shin, W. G., Scheckman, J. H., \& Pui, D. Y. H. (2009). Structural Properties and Filter Loading Characteristics of Soot Agglomerates. Aerosol Science and Technology, 43(10), 1033-1041. http://doi.org/10.1080/02786820903131081

Kondo, K., Aizawa, T., Kook, S., \& Pickett, L. (2013). Uncertainty in Sampling and TEM Analysis of Soot Particles in Diesel Spray Flame. http://doi.org/10.4271/2013-01-0908

Kook, S., Zhang, R., Chan, Q. N., Pickett, L. M., Cenker, E., Bruneaux, G., ... Nordin, E. Z. (2015). Automated Detection of Primary Particles from Transmission Electron Microscope ( TEM ) Images of Soot Aggregates in Diesel Engine Environments. SAE International, accepted. http://doi.org/10.4271/2015-01-1991

Köylü, Ü. Ö., Faeth, G. M., Farias, T. L., \& Carvalho, M. G. (1995). Fractal and projected structure properties of soot aggregates. Combustion and Flame, 100(4), 621-633. http://doi.org/10.1016/0010-2180(94)00147-K

Liu, F., Yon, J., \& Bescond, A. (2015). On the radiative properties of soot aggregates - Part 2: Effects of coating. Journal of Quantitative Spectroscopy and Radiative Transfer. http://doi.org/10.1016/j.jqsrt.2015.08.005

Mirzaei, M., \& Rafsanjani, H. K. (2017). An automatic algorithm for determination of the nanoparticles from TEM images using circular hough transform. Micron, 96, 86-95.

http://doi.org/10.1016/j.micron.2017.02.008

Motzkus, C., Macé, T., Gaie-Levrel, F., Ducourtieux, S., Delvallee, A., Dirscherl, K., ... Vaslin-Reimann, S. (2013). Size characterization of airborne SiO2 nanoparticles with on-line and off-line measurement techniques: An interlaboratory comparison study. Journal of Nanoparticle Research (Vol. 15). http://doi.org/10.1007/s11051-013-1919-4

Otsu, N. (1979). A Threshold Selection Method from Gray-Level Histograms. IEEE Transactions on Systems, Man, and Cybernetics, 9(1), 62-66. http://doi.org/10.1109/TSMC.1979.4310076

Ouf, F.-X., Mocho, V.-M., Pontreau, S., Wang, Z., Ferry, D., \& Yon, J. (2014). Clogging of Industrial High Efficiency Particulate Air (HEPA) Filters in Case of Fire: From Analytical to Large-Scale Experiments. Aerosol Science and Technology, 48(9), 939-947. http://doi.org/10.1080/02786826.2014.947022

Ouf, F. X., Yon, J., Ausset, P., Coppalle, A., \& Maillé, M. (2010). Influence of Sampling and Storage Protocol on Fractal Morphology of Soot Studied by Transmission Electron Microscopy. Aerosol Science and Technology, 44(11), 1005-1017. http://doi.org/10.1080/02786826.2010.507228

R'mili, B., Le Bihan, O. L. C., Dutouquet, C., Aguerre-Charriol, O., \& Frejafon, E. (2013). Particle Sampling by TEM 
Grid Filtration. Aerosol Science and Technology, 47(7), 767-775.

http://doi.org/10.1080/02786826.2013.789478

Ribeyre, Q., Grévillot, G., Charvet, A., Vallières, C., \& Thomas, D. (2014). Modelling of water adsorptioncondensation isotherms on beds of nanoparticles. Chemical Engineering Science, 113, 1-10. http://doi.org/10.1016/j.ces.2014.03.027

Schmid, O., \& Stoeger, T. (2016). Surface area is the biologically most effective dose metric for acute nanoparticle toxicity in the lung. Journal of Aerosol Science, 99, 133-143.

http://doi.org/10.1016/j.jaerosci.2017.09.017

Sing, K. S. W. (1985). Reporting physisorption data for gas/solid systems with special reference to the determination of surface area and porosity (Recommendations 1984). Pure and Applied Chemistry, 57(4), 603-619. http://doi.org/10.1351/pac198557040603

Steiner, S., Bisig, C., Petri-Fink, A., \& Rothen-Rutishauser, B. (2016). Diesel exhaust: current knowledge of adverse effects and underlying cellular mechanisms. Archives of Toxicology, 90(7), 1541-1553. http://doi.org/10.1007/s00204-016-1736-5

Thomas, D., Ouf, F. X., Gensdarmes, F., Bourrous, S., \& Bouilloux, L. (2014). Pressure drop model for nanostructured deposits. Separation and Purification Technology, 138, 144-152. http://doi.org/10.1016/j.seppur.2014.09.032

Wang, C., Chan, Q. N., Zhang, R., Kook, S., Hawkes, E. R., Yeoh, G. H., \& Medwell, P. R. (2016). Automated determination of size and morphology information from soot transmission electron microscope (TEM)generated images. Journal of Nanoparticle Research, 18(5), 1-15. http://doi.org/10.1007/s11051-0163434-x

Yon, J., Bescond, A., \& Liu, F. (2015). On the radiative properties of soot aggregates part 1: Necking and overlapping. Journal of Quantitative Spectroscopy and Radiative Transfer, 162, 197-206. http://doi.org/10.1016/j.jqsrt.2015.03.027

Yon, J., Liu, F., Bescond, A., Caumont-Prim, C., Rozé, C., Ouf, F. X., \& Coppalle, A. (2014). Effects of multiple scattering on radiative properties of soot fractal aggregates. Journal of Quantitative Spectroscopy and Radiative Transfer, 133, 374-381. 


\section{Supplementary material: sensitivity of specific surface area to primary particle diameter, overlap coefficient and density}

The sensitivity of the relation (III) used to determine the surface specific area regarding the different input parameters has been proofed using a random normal distribution for each influent parameter.

The study has been performed in two steps:

1. Each parameters have been tested separately on 10000 random values following a normal distribution (the others have been fixed at their respective mean value).

2. All parameters have been tested on a 10000 random values following a normal distribution.

The standard deviation has been computed for each of the cases and details of these tests are reported in table S1.

Table S2: Test matrix for sensitivity analysis

\begin{tabular}{|c|c|c|c|}
\hline Case & $D_{p p}$ & $\rho_{p p}$ & $\mathrm{C}_{\mathrm{ov}}$ \\
\hline 1 & $26.5 \mathrm{~nm}$ & $1543 \mathrm{~kg} / \mathrm{m}^{3}$ & $\begin{array}{c}10000 \text { random values following a normal } \\
\text { distribution (mean }=0.11 \text {, coefficient of } \\
\text { variation } 40 \% \text { ) }\end{array}$ \\
\hline 2 & $26.5 \mathrm{~nm}$ & $\begin{array}{c}10000 \text { random values following a normal } \\
\text { distribution (mean=1543 kg/m } \mathrm{m}^{3} \text {, coefficient } \\
\text { of variation } 5 \% \text { ) }\end{array}$ & 0.11 \\
\hline 3 & $\begin{array}{c}10000 \text { random values following a normal } \\
\text { distribution (mean=26.5 nm, coefficient of } \\
\text { variation } 20 \% \text { ) }\end{array}$ & $1543 \mathrm{~kg} / \mathrm{m}^{3}$ & 0.11 \\
\hline 4 & $\begin{array}{c}10000 \text { random values following a normal } \\
\text { distribution (mean=26.5 nm, coefficient of } \\
\text { variation } 20 \% \text { ) }\end{array}$ & $\begin{array}{c}10000 \text { random values following a normal } \\
\text { distribution (mean=1543 } \mathrm{kg} / \mathrm{m}^{3} \text {, coefficient } \\
\text { of variation } 5 \% \text { ) }\end{array}$ & $\begin{array}{c}10000 \text { random values following a normal } \\
\text { distribution (mean }=0.11 \text {, coefficient of } \\
\text { variation } 40 \% \text { ) }\end{array}$ \\
\hline
\end{tabular}

Results are presented in figure $\mathrm{S} 1$ for $10,100,1000$ and 10000 primary particles $\left(\mathrm{N}_{\mathrm{pp}}\right)$. According to figure S1, the standard deviation associated to the primary particle diameter has the highest influence on the relative deviation of the specific surface area while density, as expected, has the lowest influence. On the other hand and surprisingly, the overlap coefficient, denoting a standard deviation of $40 \%$, has similar influence than density (with estimated standard deviation close to $5 \%$ ). Such poor influence of the overlap coefficient explains why, even with $40 \%$ of uncertainty on this parameter, the SSA values obtained according to our automatic analysis software are in close agreement with those measured by BET. 


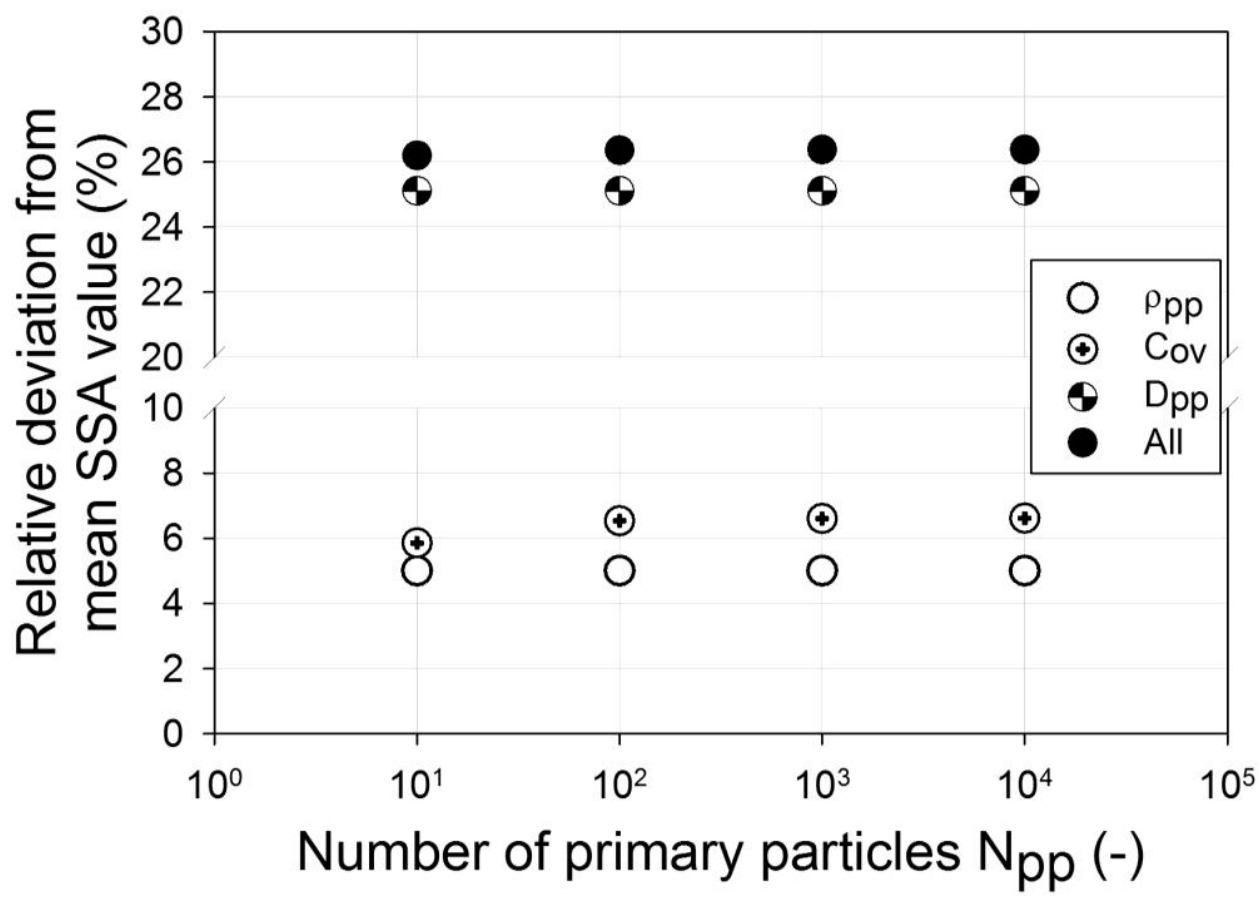

Figure S3: Evolution of the relative deviation from mean specific surface area value as a function of number of primary particles associated to separate uncertainty of density, overlap coefficient and primary particle diameter. "All" corresponds to the relative deviation when all uncertainties are considered in the same time. 